\title{
NIETZSCHE Y SU "ÉTICA DE LA AMISTAD": CON Y CONTRA LA TRADICIÓN ${ }^{1}$
}

\author{
Nietzsche and his "ethics of friendship": With and against tradition
}

\author{
Diana Aurenque*
}

\section{RESUMEN}

Si bien la amistad representa uno de los fenómenos más típicamente humanos, ella no ha ocupado un lugar protagónico en la lista de las grandes preguntas y temas de la filosofía. Con todo, la amistad ha sido una cuestión que, pese a marginal, posee una tradición en la filosofía. Precisamente la concepción de la amistad de Nietzsche se ubica en y contra esa tradición. En la presente contribución no pretendo ofrecer una visión exhaustiva sobre la "ética de la amistad" de Nietzsche, sino más bien caracterizar sistemáticamente algunos de sus planteamientos centrales. Se trata de exponer los aspectos fundamentales de la comprensión nietzscheana sobre la amistad, contextualizando dicha comprensión en el marco general del pensar del filósofo. En

\footnotetext{
${ }^{1}$ El presente texto fue presentado como por primera vez en las Cuartas Jornadas Filosóficas: la amistad en la filosofía, organizada el Instituto de Filosofía, de la Facultad de Filosofía y Humanidades de la Universidad Austral de Chile. Agradezco los comentarios recibidos en esa ocasión, pero muy particularmente agradezco a Félix Duque por sus valiosas orientaciones y sugerencias. También agradezco las críticas y sugerencias de los revisores anónimos de este trabajo. Finalmente, señalo que este texto es resultado parcial del Proyecto de Investigación FONDECYT de Iniciación 2015, №11150298, de la que soy Investigadora Responsable.
}

* Departamento de Filosofía, Facultad de Humanidades, Universidad de Santiago de Chile. Santiago, Chile. Correo electrónico: diana.aurenque@usach.cl

Artículo recibido el 28 de marzo de 2017. Aceptado el 12 de abril de 2018. 
lo sucesivo me referiré a cuatro dimensiones en las que, a mi juicio, se desarrolla la meditación nietzscheana sobre la amistad: a) La amistad como praxis ética; b) La relación entre amor, matrimonio y amistad; c) La rehabilitación del enemigo, y d) La amistad como praxis política. Al final daré algunas conclusiones que permitirán reconocer en Nietzsche un filósofo que piensa siempre con y contra la tradición.

Palabras clave: Nietzsche, ética de la amistad, enemigo, amor y amistad, comunidad auténtica.

\begin{abstract}
Although friendship represents one of the most typically human phenomena, it has not had a leading place in the list of the main questions and themes of philosophy. Nevertheless, friendship has been an issue that even if marginal, has indeed a tradition in philosophy. Precisely Nietzsche's conception of friendship is located in and against that tradition. In this contribution I do not intend to offer a comprehensive view of Nietzsche's "ethics of friendship", but rather to systematically characterize some of its central approaches. I will focus on the fundamental aspects of the Nietzschean understanding of friendship, contextualizing that understanding in the general framework of the philosopher's thinking. For that purpose, I will explain four aspects in which, in my opinion, we can explain Nietzsche's thinking on friendship: a) Friendship as ethical praxis; b) the relationship between love, marriage and friendship; c) the rehabilitation of the enemy, and d) friendship as political praxis. Finally, I will offer some conclusions that may allow us to recognize in Nietzsche a philosopher who always thinks with and against the tradition.
\end{abstract}

Keywords: Nietzsche, ethics of friendship, enemy, love and friendschiep, authentic community.

\title{
1. Introducción: pensando la amistad desde la filosofía
}

Al menos desde Aristóteles en adelante, la amistad es considerada por lo general a partir de un plano moral. La amistad en cuestión es definida como una "virtud fundamental que se expresa en la benevolencia recíproca consciente entre dos seres humanos", y que posee un genuino "carácter moral" solo cuando se cumplen otras condiciones como "amor recíproco", "respeto", "apertura" y "confianza incondicionada" (Schischkoff, 19912, p. 20). En la filosofía antigua Aristóteles representa, en efecto, uno de los pocos filósofos 
que se dedica a reflexionar seriamente sobre este fenómeno. Si bien antes que él, Platón le dedicó algunas meditaciones al tema, no le concede la importancia filosófica que tiene la amistad en la obra aristotélica. Posteriormente, Epicúreo y los Estoicos seguirán las enseñanzas aristotélicas de la amistad y destacarán su importancia para la vida humana. Sin embargo, durante la Edad Media la amistad pasará a ser vista no tanto como un vínculo entre seres humanos (hombres y libres), sino más bien como una unión posible gracias a la gracia y amor divino (HWPh, 1972, p. 1107). Con la cristianización de la cultura, la amistad es desligada cada vez más drásticamente del amor sensible y relacionada más fuertemente a Dios. Justamente mediante la secularización del pensamiento que ocurre ya en la modernidad, la amistad vuelve a ser concebida como una actividad humana, y reubicada en la sociedad. Más adelante, sobre todo con el romanticismo alemán, reaparecerá la amistad, pero en oposición a la noción de amor entre géneros; en efecto, la amistad será idealizada vinculándola a un ideal casi trascendente. (HWPh, 1972, p. 1108). En esos años se acuña la expresión alemana Herzensfreund, literalmente amigo de corazón, que alude a una amistad con una fuerte unión espiritual (HWPh, 1972, p. 1108). Schlegel, por ejemplo, definirá a la amistad como "reingeistige Liebe", es decir, como "amor puramente espiritual" (HWPh, 1972, p. 1110). En un giro ontológico bastante posterior, Heidegger dirá a principios de los años treinta que el filósofo representa al "Freund des Seins"-amigo del ser (Heidegger, 1988, p. 82). Nietzsche, por su parte, se distingue prácticamente de todas las concepciones mencionadas, pero no sin mantener una fuerte relación con la tradición aristotélica. Por ello, será útil detenernos un poco en la concepción del Estagirita.

Aristóteles le otorga a la amistad una particularidad fundamental en su obra. El filósofo advierte que la amistad, en tanto ideal, expresa condiciones antropológicas específicas que busca potenciar. Se trata de aquellas capacidades propias de la naturaleza del ser humano en tanto zoon politikon, como un animal social-político-cívico, y como zoon logon echon, como animal dotado de lenguaje y razón. Ahora bien, en Aristóteles es innegable la presencia de una tensión entre ambas capacidades en cuanto involucran formas de vida distintas (la política y la filosófica). Aristóteles resaltará, por un lado, el valor de la vida filosófica:

$\mathrm{Si}$, entonces, la función propia del hombre es una actividad del alma según la razón, o que implica la razón, y sí, por otra parte, decimos que esta función es específicamente propia del hombre y del hombre bueno, [...] siendo esto así, decimos que la función del hombre es una cierta vida, y ésta es una actividad del alma y unas acciones razonables, y la del hombre bueno estas mismas 
cosas bien y hermosamente, y cada uno se realiza bien según su propia virtud; y si esto es así, resulta que el bien del hombre es una actividad del alma de acuerdo con la virtud, y si las virtudes son varias, de acuerdo con la mejor y la más perfecta, y además en una vida entera (Aristóteles, 1098a, p. 144).

Por otra parte, enfatiza el bien político, y con ello, la vida política como un bien mayor que el bien individual:

Pues aunque sea el mismo el bien del individuo y el de la ciudad, es evidente que es mucho más grande y más perfecto alcanzar y salvaguardar el de la ciudad; porque procurar el bien de una persona es algo deseable, pero es más hermoso y divino conseguirlo para un pueblo y para ciudades (Aristóteles, 1094b, p.133).

Pese a esa tensión, es importante entender la complementariedad entre ambas formas de vida, pues, justamente la relación entre teoría (filosofía) y praxis (política y ética) se comprenden a partir de sus precedentes filosóficos, en particular, del denominado intelectualismo moral socrático (Santa-María, 2008, pp. 115-150.). De aquí es posible contextualizar la cita: "Pero la amistad perfecta es la de los hombres buenos e iguales en virtud." (Aristóteles, 1156b6,7, pp. 328). En tanto la "vida buena" o la "felicidad" (eudaimonia) se realiza en la bios teoretikos no de un eremita, sino de un ciudadano de la polis, rodeado de y con otros, desplegando prácticas éticas y sociales determinadas -las virtudes aristotélicas-, la amistad tendrá un papel importante que desempeñar. Pues, para Aristóteles, la amistad constituye justamente una de esas capacidades sociales que permiten la realización ética de los individuos. La buena vida en tanto es orientada por virtudes, ocurre maximizando las potencialidades más nobles de los seres humanos, para así conducirlos a una constante optimización -excelencia moral que va de la mano con la excelencia racional. Ahora bien, pese a que Aristóteles distingue entre tres formas de amistad, amistad por placer, por utilidad y por virtud (Aristóteles, $1156^{\mathrm{a}}$, pp. 326-333), aquella que él enaltece por sobre otras corresponde a la amistad comprendida como un amor recíproco entre iguales y virtuosos.

Al comienzo de los libros XVIII y IX de la Ética a Nicómaco, Aristóteles hace referencia a la relación entre amistad y virtud. El hombre virtuoso para Aristóteles es quien se mantiene a sí mismo en una distancia reflexiva; constituye un observador de sí mismo capaz de evaluar moralmente sus acciones. En este sentido, también los virtuosos necesitan de un otro, de un otro sí-mismo y que en el caso aristotélico recae en el amigo, ya que este les permite ser y conocerse mejor. Esto nos muestra una forma especial de 
entender la amistad en relación a la diada mismidad/alteridad; mientras que, en Sócrates, por ejemplo, y usando la expresión de Hannah Arendt, el hombre virtuoso es "dos en uno", aludiendo así a la relación amistosa entre uno y su propia conciencia moral y autoconocimiento (Arendt, 1979, p. 186); el amigo en cambio, constituye para Aristóteles otro sí-mismo. En este sentido, la amistad requiere precisamente asumir que el amigo es un otro "sí mismo", se acepta la repetición de la autoconciencia reflexiva de un individuo en el resto de la sociedad.

Ese tipo de amistad no tiene que ver con una relación de interés, utilidad o placer, sino que es un vínculo distinto y menos común que no conduce en primera instancia a una alegría individual, sino que constituye una posibilidad de perfeccionamiento ético. Como sostiene Hübenthal sobre la amistad en Aristóteles: "Como un "yo extendido" [...] el amigo asume la función de un estímulo (Stimulans), de un destinatario, y al mismo tiempo de un espejo de la propia actividad garantizadora de la felicidad" (Hübenthal, 2006, p. 86).

Por otra parte, la amistad no solo tiene relevancia en el plano de la realización ética individual, sino que al mismo tiempo tiene una función política. Pues, Aristóteles considera que si hay amigos no hay necesidad de justicia, pero, por el contrario, para que haya justicia debe haber amistad: "Y cuando los hombres son amigos, ninguna necesidad hay de justicia, pero, aun siendo justos, sí necesitan de la amistad, y parece que son los justos los que son más capaces de la amistad" (Aristóteles, Eth. Nic. 1155 a 27, p. 324). Así, la amistad es vista como el sustrato originario en la que la buena convivencia tanto para el desarrollo individual en medio de la vida social, así como para la prosperidad misma de la sociedad. En lo que respecta a Nietzsche, veremos que es posible identificar aspectos muy similares entre su concepción de amistad y la de Aristóteles -aunque desde luego, bajo supuestos distintos.

\section{Filosofía y biografía}

Hay dos perspectivas claras desde las cuales puede ser interpretado y reconstruido el significado de la amistad para Nietzsche: el plano biográfico y el plano puramente filosófico. Como nos dice Karl Jaspers en su monografía sobre Nietzsche (1950), si bien el filósofo se caracterizó por llevar una existencia solitaria, en su vida cultivó diversas y variadas amistades - tal como atestiguan un sinnúmero de cartas. Estos documentos no solo nos permiten un acceso a la vida personal de Nietzsche, sino también a su pensar. Destaca además que Nietzsche cultivó amistad con personalidades notables de su época -Jacob Burckhardt, Richard Wagner, Heinrich von Stein, Karl Hillebrand, Cosima 
Wagner o Hans von Bulow por nombrar algunos (cf. Treiber 2011, pp. 35-49; Jaspers, 1950). Sin duda, la mayoría de sus apreciaciones y consideraciones filosóficas sobre la amistad tienen que ver con la propia experiencia: con su amistad temprana con los compañeros de primaria Wilhelm Pinder y Gustav Krug; con Erwin Rohde, así como con el historiador y orientalista Paul Deussen, o su amistad con el médico Paul Reé y con la escritora y psicoanalista Lou Andreas-Salome. Por supuesto, su amistad con Richard Wagner, quien era 30 años mayor que Nietzsche, será aquella que junto con la amistad con Erwin Rohde (Jaspers, 1950, p. 59) dejarán las huellas más profundas en su vida. Tras la ruptura con Wagner, más o menos en el año 1876, Nietzsche cae en una gran soledad. Pero luego vendrán otras amistades -por ejemplo, el compositor Heinrich Köselitz (alias Peter Gast) y los ya mencionados Paul Reé y L. A. Salome, con quienes mantiene una intensa, aunque relativamente breve amistad. Tras el nuevo fracaso, Nietzsche comienza a aislarse cada vez más. Y en concordancia con ello, cambian también sus consideraciones sobre la amistad. Comenzará a defender con énfasis la necesidad de mantener distancias y justifica ver la amistad con cierta desconfianza. Nietzsche estilizará cada vez más la "soledad heroica del genio solitario" (Lemke, 2011, p. 238), posición que se diferencia abiertamente con sus meditaciones tempranas, más bien positivas sobre la amistad. Uno de los pocos amigos que permanece fiel durante toda la vida de Nietzsche será el teólogo Franz Overbeck. De todas sus amistades, la amistad truncada con Richard Wagner constituye un hecho que torturará a Nietzsche por largo tiempo. Particularmente el caso específico de la amistad con Wagner permite introducirnos a la comprensión nietzscheana de la amistad en algunos de sus aspectos fundamentales. Pues, Nietzsche encuentra en Wagner al verdadero amigo, como veremos más adelante, justamente en tanto un igual, un otro "que por la misma causa busca una renovación cultural" (Lemke, 2011, p. 238).

Desde la perspectiva filosófica resulta innegable que para Nietzsche la amistad es un tema central en su filosofar, pero que solo desde hace unos años ha despertado el interés de comentadores y estudiosos de su obra (Lemke, 2011, p. 237; Holst, 2011, p. 36; 2013). Como pocos filósofos de su tiempo, Nietzsche no solo se interesa por este tema, sino que además sus meditaciones al respecto están influidas ante todo por los antiguos griegos y recuerdan justamente a Aristóteles, a los Estoicos y Epicúreos (Windelband, 1957, 15, pp. 128-150). Como Holst sostiene: "Nietzsche hace ciertamente una crítica dura del fundamento metafísico de la moralidad y de la epistemología griega, sobre todo de Platón, pero en su valoración de la amistad como un fenómeno ético destacado se apoya en la filosofía griega" (Holst, 2011, p. 38). De aquí 
se explica que, en la actualidad, algunos autores han comenzado a hablar de una "filosofía de la amistad" en Nietzsche (Lemke, 2011). Ciertamente, una de las cosas que más rescata Nietzsche de la filosofía clásica será precisamente la importancia que tiene la amistad para la ética de los griegos (cf. Nietzsche, NF$1869,1[52]$, p. 75). No obstante, a diferencia de los griegos, Nietzsche centra su atención en la amistad con una mirada particular y de tipo genealógicofisiológica. Esto quiere decir, que su interés radica en exponer los supuestos escondidos, a-morales o como él también los llama, psicológicos de la amistad. Sin perjuicio de lo anterior y contrario a los que a veces se afirma, ello no significa que Nietzsche no tenga una visión en cierto sentido ideal de la amistad (cf. HWPh Bd. 2, p. 1113).

\section{La amistad como praxis ética}

Nietzsche considera que la amistad pertenece al grupo de fenómenos que la filosofía en cuanto metafísica no ha estudiado en detalle. En el famoso aforismo número 7 de la Gaya ciencia titulado Algo para laboriosos, donde Nietzsche plantea lo que puede denominarse como su propio programa filosófico -y por ello, no está ausente ahí su poderosa crítica al curso metafísico de la filosofía-, enfatiza la necesidad de replantear los fundamentos filosóficos y fisiológicos de nuestra cotidianidad social, moral y afectiva. En este sentido, se referirá a la necesidad de una "historia del amor, de la codicia, de la envidia, de la conciencia, de la piedad, de la crueldad", se preguntará también "si se conocen los efectos morales de los alimentos" o si "hay una filosofía de la alimentación" para así avanzar y seguir preguntando retóricamente si ha sido expuesta "la dialéctica del matrimonio y de la amistad". (Nietzsche, FW-7, p. 744). Como podemos observar, está puesta al descubierto de una serie de temas olvidados y no tratados por la metafísica, tiene por objeto incorporar el materialismo en el centro mismo de la filosofía. Más adelante, veremos que rehabilitar la importancia y significado filosófico de algunos de los mencionados temas y problemáticas tienen directa relación con plantear a la amistad como asunto filosófico.

No es muy conocido que Nietzsche en sus fragmentos póstumos menciona explícitamente una "ética de la amistad" (Ethik der Freundschaft) (Nietzsche, NF-1876, 19[9], p. 270). Según Lemke, quien es uno de los primeros que comenzó a estudiar el tema, esta ética de la amistad debe entenderse "en cuanto forma de vida" (Lemke, 2011, p. 238). Ahora bien, la "ética de la amistad" propuesta se distingue de forma radical de una consideración moralizadora de la amistad. De acuerdo a Nietzsche, la relación entre amistad y moral es 
consecuencia de que su sentido originario, aristotélico, haya pasado por el filtro judeocristiano (hecho además fortalecido con la irrupción del romanticismo alemán que sin duda idealiza la amistad). La amistad bajo el prisma cristiano, quiere describir "la acción no egoísta" y por ello "según la concepción hoy día habitual de la moralidad, la relación amistosa es la relación más moral que existe" (Nietzsche, NF-1876, 23[106], p. 349). Nietzsche criticará esta forma presuntamente altruista de comprender la amistad y propondrá una concepción en la que el individuo siempre está en el centro y, sin embargo, precisamente por ello puede ser amigo.

Sin duda, la crítica de Nietzsche es interesante porque rechaza y renueva a la vez el significado moral que contiene la amistad. Por un lado, critica la interpretación moralizadora de la amistad centrada en los supuestos altruistas de la tradición judeo-cristiana; pero, por otro lado, Nietzsche se mantiene Aristotélico y apela por reconocer en ella una virtud. De este modo, Nietzsche considera que la amistad, al igual que otras virtudes, se cultiva a través de una praxis de vida determinada. La alternativa para Nietzsche no está en la negación de los propios intereses qua rechazo del ego, sino en enfatizar el lazo con el otro desde la vitalidad. Para ello, Nietzsche propone a la jovialidad como el sentimiento capaz de unir a los seres humanos en verdadera amistad, y con ello contradice la ética de la muerte, como llama Nietzsche a la moral cristiana, que privilegia el sentimiento de la compasión (requisito según su maestro Schopenhauer para la "achten Freundschaft"). La jovialidad es escogida como el sentimiento que nos une con otros y nos reafirma en la existencia. En efecto, en un fragmento póstumo de 1876 nos dice:

Quienes saben alegrarse con nosotros están por encima y más cerca de nosotros que quienes nos compadecen. La alegría compartida [Mitfreude] hace al "amigo" (al que se alegra con nosotros [Mitfreuende]): la compasión, al compañero de desgracias. Una ética de la compasión requiere como complemento la ética, aún más elevada, de la amistad [Ethik der Freundschaft] (Nietzsche, NF-1876, 19[9], p. 270).

En la medida en que la amistad es una virtud que debe ser desarrollada mediante una praxis determinada, Nietzsche propone a la jovialidad como condición de posibilidad para su ética de la amistad. Esto, sin duda, es novedoso, pues, contrario a la reunión de amigos en torno a un bien, un interés o un placer común (como señala Aristóteles), o a la empatía común del padecer (Schopenhauer), Nietzsche propone que la jovialidad es el sentimiento idóneo para afirmar la vida. De aquí se explica que Zaratustra no enseña sobre el "prójimo", sino del "amigo", a saber, de quien puede ser "celebración de la tierra 
y un presentimiento del sobre/superhombre"; todo esto por medio justamente de la jovialidad común, de la alegría común. "Freude"-Jovialidad-y "Freund" -amigo-son, pues, palabras que no solo se asemejan en su etimología, sino que además son co-pertenecientes. La jovialidad de quienes se alegran en conjunto y no la com-pasión, no se cansa de repetir el filósofo, corresponde a aquello que "hace al amigo". Evidentemente, Nietzsche elige a la jovialidad como el modo de afectividad adecuado para su ética de la amistad porque necesita un sentimiento capaz de servir de contrapeso al sufrimiento y a la pesadez propios de la ética cristiana-platónica y de su desprecio a la vida. También por ello, Nietzsche repetirá en su Zaratustra la importancia de la risa (Lachen) en oposición al sufrimiento del Dios crucificado.

\section{La relación entre amor, matrimonio y amistad}

Recordemos que la antigua palabra griega para amistad (philia) demuestra una conexión con el amor (pero no en sentido cristiano del caritas) (Helm, 2017). Para Nietzsche, la amistad, así como todas nuestras fuerzas, deseos y motivaciones tienen fuentes fisiológicas. También el amor tiene un asidero fisiológico. Así nos dirá Nietzsche ya en 1871 que: "Toda inclinación, amistad y amor son al mismo tiempo algo fisiológico. Nosotros ignoramos aún cuán profundo y cuán alto llega la Physis" (Nietzsche, NF-1871,16[42], p. 337). A esta naturalización de los fenómenos morales me referiré más delante.

Contra la idealización del matrimonio y del amor de acuño judeocristiano, que encuentra su apogeo en el último tercio del siglo XVIII con la introducción del "matrimonio por amor" (Ehe aus Liebe), Nietzsche ofrece una interpretación de la amistad como elemento fundante y sostenedor de un buen matrimonio, así como manifestación paradigmática de un amor más elevado. Nietzsche critica la versión cristianizada y romantizada del amor en tanto este, de acuerdo a su interpretación, representa un rechazo y una negación de las fuerzas vitales de la existencia al ser únicamente expresión de un discurso normativo cultural.

En una serie de aforismos tanto de su obra publicada como póstuma, Nietzsche describe al "buen" matrimonio como aquel en el que impera ante todo la amistad por sobre otras virtudes. En un fragmento de 1876 nos dirá Nietzsche: "No la ausencia del amor, sino la ausencia de la amistad es lo que hace infeliz a los matrimonios" (Nietzsche, NF-1876,23[72], p. 341). Aquí Nietzsche expresa claramente que la felicidad del matrimonio depende de una forma de amor distinta al amor romántico. En diversos pasajes se refiere a la importancia del "talento para la amistad" como clave de un buen matrimonio: 
"Amistad y matrimonio. Al mejor amigo le tocará probablemente la mejor esposa, porque el buen matrimonio reposa sobre el talento para la amistad" (Nietzsche, MA-378, p. 213).

En otro lugar dirá más claramente:

Lo mejor del matrimonio es la amistad. Es ésta es lo bastante grande, permite prescindir de forma atenuada y pasar por alto lo afrodisíaco. Sin amistad, el matrimonio vulgariza a ambas partes en su modo de pensamiento y las hace del todo despreciables (Nietzsche, NF-1876,18[37], p. 264).

De acuerdo a Nietzsche lo afrodisíaco es pasajero, mientras que la amistad es de un tipo distinto, más duradero. Esto se entiende mejor si lo vinculamos al aforismo A todo lo que se llama amor de la Gaya ciencia. En el texto, Nietzsche comienza formulando una crítica al concepto tradicional de amor en tanto posesión del ser amado (eros). Nos dirá que, pese a sonar contradictorio, entre "amor y codicia" opera posiblemente una relación estructural que bien "podría tratarse del mismo impulso al que se le han puesto dos nombres diferentes". El impulso de "posesión", de "propiedad", en el caso de la codicia y del amor serían, pues, análogos. Ambos en tanto anhelos tienden a buscar lo "nuevo" y a hartarse de la seguridad:

El placer que sentimos con nosotros mismos quiere mantenerse transformando continuamente algo nuevo en nosotros mismos, -eso quiere decir precisamente poseer hartarse de algo que se posee es hartarse de sí mismo.

Ahora bien, justamente al final del aforismo Nietzsche se refiere a un amor "más elevado" que relaciona con la amistad (un amor que es philia):

Aunque de vez en cuando hay sobre la tierra una especie de continuación del amor en la que ese ávido anhelo mutuo de dos personas deja lugar a un deseo y una codicia nuevos, a una sed superior y común de un ideal que está por encima de ellos: ¿pero quién conoce este amor? ¿Quién lo ha vivido? Su verdadero nombre es amistad (Nietzsche, FW-14, pp. 748-9).

De este pequeño párrafo se desprenden dos importantes consecuencias. La amistad puede ser concebida, por un lado, como una "extensión" o "continuación" del amor en tanto logra unir a dos sin abolir, sino manteniendo la diferencia radical que conforma cada uno en su individualidad. Por otro lado, aquella trascendencia de dos en un tercero, en un ideal (como sostiene "una sed superior y común de un ideal que está por encima de ellos"), es análoga a la manera en que Nietzsche concibe la forma creadora de la existencia: la obra o 
los ideales son resultado del reconocimiento individual que se vuelve elemento común de cohesión. La importancia de la trascendencia en una obra, o en el caso de la amistad, en lo común que va más allá de los amigos, se entiende al recordar que para Nietzsche el arte de la transfiguración corresponde al supuesto metafísico que rige las fuerzas vitales de la existencia humana. En relación a esto, cobra más sentido la relación antes presentada sobre la amistad y el matrimonio, pues justamente en la creación de un tercero más noble y más libre ve Nietzsche la justificación del matrimonio; siendo un matrimonio exitoso justamente aquel entre amigos: "No solo debes enraizarte, sino también crecer hacia arriba! ¡Que para ello te sirva el jardín del matrimonio!" (Nietzsche, $\mathrm{Za}$, p. 111). Esto hay que leerlo con cuidado para evitar confusiones, pues si bien Nietzsche insiste en distinguir la amistad del amor sexual, por otro lado, y en cuanto relaciona a la amistad con el matrimonio, también relacionará a la amistad con la procreación. Siguiendo la cita anterior, para Nietzsche el matrimonio que cultiva la verdadera amistad entre ellos podrá crear un tercero más noble; pero, no cualquier matrimonio puede hacerlo: "Eres joven y quieres para ti hijo y matrimonio. Pero yo te pregunto: ¿eres un hombre al que se le esté permitido desear un hijo?" (Nietzsche, Za, p. 111). En este aforismo Nietzsche justifica la paternidad en tanto creación de un tercero, un hijo, solo en cuanto aquel tercero trascienda a los padres; el "niño" que encarna y forma nuevos ideales. De acuerdo a Walter Kaufmann, Nietzsche considera "la procreación sin sentido como una historia principalmente insignificante", pero también afirma que ella sí puede "volverse una verdadera creación" (Kaufmann, p. 560). En este sentido, Nietzsche relaciona la diada de la amistad como condición de posibilidad de la creación de un tercero (una obra, un ideal). La obra, sea ideal, sea hijo, corresponde a aquello que deviene en resultado de amor auténtico, o sea, para Nietzsche, de amistad.

A la luz de la interpretación dada se entiende también el siguiente aforismo:

Nunca dejarse amar, sino, cuando no sienta uno movido a corresponder, evitar el amor del otro y, si fuera necesario, burlarse de él, y hasta humillarse uno ante él! Nada hace tan vulgares a los artistas (¡y a las mujeres!) como el dejarse amar. Hay que evitar ser el ideal de alguien: desperdicia así su fuerza [Kraft] en formar el solo todo un ideal propio, le engañamos y hacemos que se aleje de sí-debemos hacer todo lo posible para aclarárselo o apartarlo de un empujón- El matrimonio, una amistad debería ser el modo, ¡el modo raro! De fortalecer nuestro ideal con el ideal de otro: ¡deberíamos ver también el ideal del otro y desde él, el nuestro! (Nietzsche, NF-1880,6[191], p. 637)².

\footnotetext{
${ }^{2}$ La palabra “también” aparece en alemán en cursiva, aunque no en la traducción al español.
} 
El amor propio de la amistad constituye, pues, una relación refleja. Cada uno de los amigos mantiene su individualidad, sus ideales, pero estando en compañía uno se refleja autónomo y soberano en y desde el otro. En este sentido, el llamado a "burlarse" incluso de quienes dicen amarnos no debe ser comprendido como expresión de una mera crueldad o inhumanidad de Nietzsche. Más bien es preciso que se contextualice en su narrativa acerca de los seres humanos y espíritus libres. De acuerdo al ideal de "espíritu libre" o también del "super" o "sobre-hombre" (Übermensch) nietzscheano, cada uno debe ser constructor y, por ello también, destructor constante de sus propios ideales, atento a los límites y llamados de sus fuerzas vitales para transfigurar y trascenderse plásticamente (Aurenque, 2015).

Dado que la amistad debe fundarse en la jovialidad, como vimos, y no en el sufrimiento, en un fragmento posterior (1880) y con un tono claramente menos positivo que los aforismos anteriores, Nietzsche nos recomendará saber vivir solos: "Y el matrimonio y la amistad ¿no están también llenos de peligro al favorecer tan cruel contagio de pena? Es dificil no compartir la pena - así que deberíamos evitarnos la oportunidad de hacerlo y vivir en soledad". (Nietzsche, NF-1880,6[380], p. 666). Pese a que la jovialidad constituye el sentimiento paradigmático en la amistad, Nietzsche sostiene que no resulta fácil no empatizar con el sufrimiento de los otros. Así, Nietzsche tendrá un argumento adicional para afirmar que la amistad requiere la práctica de un carácter fuerte, confirmando así que la amistad no puede ser una praxis sin esfuerzo.

\section{La rehabilitación del enemigo}

La consideración de la amistad en Nietzsche no estaría completa en sus ejes centrales si no es expuesta la contraparte del amigo: el enemigo. A diferencia de la mayoría de las concepciones tradicionalmente negativas para con la enemistad, como sostiene paradigmáticamente Platón, Nietzsche considera que tener un enemigo corresponde a una ocasión especialmente próspera para fortalecer la individualidad. Platón en su diálogo sobre la amistad Lisis -texto que trata en particular la amistad como fenómeno erótico- nos dirá Sócrates enfáticamente que un amigo y un enemigo no son lo mismo: "Pero parece increíble, Menexenes, ó más bien imposible que uno sea amigo de su enemigo y enemigo de su amigo" (Platón, p. 1871). Nietzsche, a su modo, nos plantea contrariamente que uno puede (incluso debe) reconciliarse amistosamente con el enemigo e incluso valorarlo por sobre un amigo. De aquí se entiende que Nietzsche, parafraseando la famosa frase adjudicada a Aristóteles según Diógenes, "Oh amigos, no hay amigos", señale que ella corresponde a la frase 
del "sabio agonizante" (Aristóteles); mientras que la frase "Enemigos, no hay enemigos" correspondería al llamado de "el loco viviente" (Nietzsche, MA376, p. 212). En concordancia con su consideración productiva de la pugna, de lo agonal, Nietzsche contempla justamente en el enemigo una fuerza vital fundamental que permite reafirmar la particularidad de la existencia singular. Por eso nos dirá: "La vida del enemigo - Quien vive de la lucha con su enemigo, está interesado en que permanezca con vida" (Nietzsche, MA-531, p. 249). En cuanto el enemigo no sucumbe, por oposición de fuerzas, su contrario se hará más fuerte. Esta visión altamente positiva del efecto estimulante del obstáculo tiene por fundamento la teoría de la "voluntad de poder" de Nietzsche. Según esta teoría, todos los organismos vitales desarrollan más fuerza, más poder vital en la medida en que son confrontados con obstáculos, mejor aún, con fuerzas similares o mayores que nos hacen resistencia. En Ecce homo Nietzsche articula la lucha, la amistad y el poder con particular nitidez:

Otra cosa es la guerra. De acuerdo a mi tipo, yo soy guerrero. Atacar pertenece a mis instintos. Poder ser enemigo - eso quizás presupone una naturaleza fuerte, al menos es condición en cualquier naturaleza fuerte. Ella necesita obstáculos, por lo tanto busca obstáculos: el pathos agresivo pertenece necesariamente tanto a la fuerza como al sentimiento de venganza y de desgano a la debilidad" (Nietzsche, EH 7/traducción DA.).

Para Nietzsche el enemigo representa a alguien que sabe de nosotros incluso más y mejor que aquellos que se dicen nuestros amigos: "Pero cuando nos damos cuenta de que algún enemigo nuestro nos conoce, en un punto mantenido en secreto, tan bien como nosotros nos conocemos, iqué grande es entonces nuestro disgusto!" (Nietzsche, MA-352, p. 206). Es más, Nietzsche considera no solo que los enemigos pueden saber más de nosotros mismos, sino que además nos son más similares, en tanto fuerzas contrarias de igual magnitud, que nuestros amigos, y, por tanto, fuerzas a partir de las cuales nos definimos de algún modo. Es por ello que Nietzsche aconseja tener enemigos respetables. Al mismo tiempo, de aquí se entiende Nietzsche la dura frase de Ecce homo: "El hombre del conocimiento (Erkenntnis) no solo debe amar a sus enemigos, sino que también debe poder odiar a sus amigos" (Nietzsche, EH, Vorwort, 4) El hombre del conocimiento al que se refiere Nietzsche, no refiere aquí al hombre de la vita contemplativa, del ideal platónico-cristiano de trascendencia de la tierra, sino al auténtico hombre del conocimiento que sabe valorar desde la tierra y es consciente del devenir de los valores, desde su propio sentir, ama y odia, por eso incluso valora el enemigo. Nietzsche le aconseja a este hombre no seguir el consejo de la ética cristiana, sino 
"odiar" a sus amigos dado que estos pueden justamente ser en realidad peores enemigos. Esto quiere decir que, si un amigo no me desafía, no se presenta como un estímulo, sino solo como una indiferencia que no me permite crecer $\mathrm{y}$ transcender, para Nietzsche eso realmente personifica a un enemigo. Para Nietzsche, los amigos no son quienes nos aceptan y apoyan o quienes nos siguen o idealizan; los verdaderos amigos son quienes tienen sus propios ideales frente a los nuestros; aquellos que tienen una independencia singular y que pueden incluso, por no seguirnos, parecer enemigos.

Nietzsche se esfuerza en mostrar que la amistad si bien es un fenómeno social, con un contenido normativo determinado, este, a fin de cuenta, remite ante todo a algún instinto o fuerza vital desconocido que busca siempre establecer y asegurar la propia "voluntad de poder" (Nietzsche, GM, p. 500). Aquí hay que tener particular cuidado en malinterpretar o moralizar la "voluntad de poder" como una suerte de ejercicio arbitrario de poderío. Muy lejos de lo anterior, es importante recordar que la "voluntad de poder" corresponde, más bien, al principio metafísico y en cierto modo irracional que de acuerdo a Nietzsche moviliza a todo organismo vivo (Aurenque, 2018). De aquí se desprende, que toda emoción, pensamiento, creencia y la filosofía entera, tienen en realidad por fundamento un sustrato fisiológico, es decir, movilizado por la voluntad de poder. Para Nietzsche, como citamos antes: "Toda inclinación, amistad y amor son al mismo tiempo algo fisiológico" (Nietzsche, NF-1871,16[42], p. 337). La amistad, así como la enemistad son a veces, pues, "usadas" en pos de un objetivo distinto de la propia moralidad:

Demostrar la propia vanidad al amigo y al enemigo. -Algunos maltratan por vanidad incluso a sus amigos en presencia de testigos a los que quieren dejar clara su superioridad: y otros exageran el valor de sus enemigos para probar con orgullo que son dignos de ellos (Nietzsche, VM-263, p. 344).

Con lo anterior, no se trata de que Nietzsche justifique que la amistad sea usada, sino solo intenta poner de manifiesto que muchas veces ella efectivamente es utilizada, inconscientemente o no, para fines que poco o nada tienen que ver con una verdadera amistad (ni con algún tipo de moralidad). Por eso, lo interesante de su propuesta consiste en que, si bien Nietzsche no determina contenidos morales específicos en su ética de la amistad, sin embargo, presenta a la amistad en el contexto de una estructura ético-política formal, que acentúa la individualidad y que permite, como veremos, la pluralidad de formas de existencia. 


\section{La amistad como praxis política}

En la base de su concepción de la amistad subyacen, como se ha mostrado, elementos pertenecientes a su ética de la jovialidad y de la individualidad. En la analogía entre amor (philia) y amistad Nietzsche parece considerar que la condición de posibilidad de una amistad auténtica requiere del reconocimiento del otro en tanto otro individuo. Solo en la medida en que uno se reconozca en la propia individualidad, puede incluso abrirse a la amistad y al amor: "Uno debe estar firme puesto en sí, uno debe pararse firmemente en sus piernas, sino uno no puede amar" (Nietzsche, EH: 305). La amistad, como veremos, constituye para Nietzsche la base primordial de una comunidad, permite una forma de vida en común distinto al modo social de comunidad de tipo "rebaño" o masa indiferenciada, precisamente porque en ella la individualidad es mantenida, reforzada y potenciada. Aquí conviene explicar un poco la crítica al grupo "rebaño".

Para Nietzsche la historia de la moral, entre "el bien y el mal", tal como la relata en Humano demasiado humano, tiene una "dúplice prehistoria del bien y el mal"; para quienes él llama la "casta de señores", aquellos "nobles", corresponden a aquellos que tienen el poder de hacer valer lo bueno con lo que efectivamente es bueno y, viceversa, lo malo con lo malo. Lo anterior puede sonar redundante, pero en realidad no lo es. Pues la supuesta redundancia quiere dejar en claro que "lo bueno" (gut) no remite a una norma -social, cultural o moral- externa a la existencia de estos nobles, sino que lo "bueno" se deriva, o mejor dicho, va en armonía con la vida misma de estos individuos; por eso, los nobles según Nietzsche saben valorar aquello que los empodera vitalmente y desechan como "malo" (schlecht) aquello que los debilita y enferma y, consecuentemente, quienes no sepan hacer valer al modo de los nobles serán llamados "malos". Por su parte, la otra cara de la prehistoria de la moral, la forman justamente quienes conforman ese grupo de débiles, la "casta de siervos", los débiles que en oposición no pueden hacer valer y son impotentes. Para efectos del estudio sobre la comprensión nietzscheana de la amistad y sus formas de conformar comunidad, resulta interesante el juicio severo que hace Nietzsche de los débiles. Para el filósofo, los débiles, a diferencia de los señores aristocráticos, solo saben estar con otros como "masa", "rebaño", es decir, como un grupo donde el individuo desaparece. Nietzsche enaltece a los nobles, como aquellos que son los únicos que tienen un genuino sentimiento comunitario:

En cuanto bueno se pertenece a los "buenos", a una comunidad que posee el sentimiento de serlo en la medida en que los individuos están obligados 
recíprocamente por el sentido de la compensación. En cuanto malo se pertenece a los "malos", una masa de hombres subordinados, impotentes, que no poseen ningún sentimiento de comunidad. Los buenos son una casta, los malos una masa como el polvo (Nietzsche, MA-45, p. 100).

Sostiene además que la casta noble no reconoce al "enemigo" (Feind) como "malvado" (böse), sino como "malo" (schlecht) y que este puede compensar (vergelten). Así nos da el ejemplo de Homero, para quien tanto el troyano como el griego eran ambos buenos. En este sentido, quien nos dañe no es considerado per se "malo", sino quien es despreciable (verächtlich). En la "comunidad" de los buenos se hereda lo bueno: "En la comunidad de los buenos, el bien es hereditario; es imposible que de un terreno tan bueno pueda nacer alguien malo (schlecht)" (Nietzsche, MA-45: 100). Con lo anterior, Nietzsche no habla de la imposibilidad de lo "malvado" en sentido de la moral, sino en sentido de algo malo para la casta y su vida. Como veremos más adelante, la amistad vista en su condición de praxis política, será proclamada por Nietzsche como la condición de posibilidad de comunidad auténtica. La amistad representa, pues, para Nietzsche la célula germinal que posibilita toda colectividad auténtica, en tanto ella es fuente y estímulo del cultivo de la propia individualidad. En el seno de los intereses de la vida en común, se posiciona la amistad con un rol fundamental. En tanto los amigos comparten ideales auténticamente, aquel compartir los vincula, pero siempre como individuos soberanos. Dicho en otros términos, en la medida en que uno trata con "buenos amigos" se potencia el ser sí mismo más propio. A diferencia de la colectividad social que se basa en otro tipo de relaciones como, por ejemplo, la funcionalidad o utilidad de la mayoría que defienden los utilitaristas, y en la que la individualidad es determinada y nivelada externamente (por sistemas normativos ajenos al reconocimiento soberano del individuo), la amistad representa para Nietzsche una alternativa de cohesionar a un grupo a partir del compromiso que cada uno tiene para consigo mismo. Ella constituye una forma especial de generar y potenciar la unión no desde un vínculo externo, como un contrato, sino desde el reconocimiento interior de los individuos sobre determinados ideales comunes.

Como vemos, en la base de la ética de la individualidad nietzscheana encontramos como elemento esencial la amistad. Pues la amistad representa para Nietzsche la instancia de comunidad auténtica donde los implicados son individuos autónomos y soberanos de sí. De acuerdo a esta visión, solo dos soberanos pueden realmente ser amigos; o, siguiendo lo expuesto anteriormente, ser enemigos. De esto se trataba justamente el aforismo "amistad celestial" dedicado a Reé (pero en realidad es a Wagner, Poetnisch, 2011, p.113): 
Amistad estelar: Éramos amigos y nos volvimos extraños. Pero está bien así, y no nos lo queremos disimular y encubrir como si tuviésemos que avergonzarnos de ello. Somos dos navíos, cada uno de los cuales tiene su meta y su rumbo [...] Que tengamos que volvernos extraños es la ley que está por encima de nosotros: iprecisamente por eso nos debemos inspirar mayor respeto! ¡Precisamente por eso el pensamiento de nuestra anterior amistad debe volverse más sagrado! Es probable que haya una curva y una órbita estelar enorme e invisible en la que pueden incluirse como pequeños trayectos nuestros caminos y metas tan diferentes, ¡Elevémonos a este pensamiento! Pero nuestra vida es demasiado corta y nuestra capacidad visual demasiado reducida como para que podamos ser más que amigos en el sentido de aquella sublime posibilidad. - Y así, creamos en nuestra amistad estelar, incluso si tuviéramos que ser enemigos terrenales (Nietzsche FW, 279, p. 831).

El aforismo, ciertamente parece resaltar la lejanía y distancia entre dos sujetos que antes se decían amigos. Pero si atendemos más detalladamente el texto, encontraremos indicios, al menos de forma indirecta, de aquello que, si bien quizás no de forma permanente, logra unir auténticamente a amigos. En este respecto, lo último me parece, para los fines de este estudio, decisivo: pues si bien en la tierra dos individuos pueden ser enemigos o defensores de ideales opuestos, si son naturalezas similares, es decir, si conocen soberanamente sus ideales y fuerzas, aunque sean enemigos circunstanciales, son semejantes "estelarmente", es decir, unidos en principio por un lazo "cósmico", el mismo que permite que las perspectivas y verdades pueden cambiar (siguiendo el monismo metafísico de Nietzsche), abriendo paso a la alternativa de que un día enemigos puedan ser amigos. Así, contra y con la tradición, Nietzsche termina considerando que la amistad no se funda en un sentimiento ni racional ni moral ni metafísico, pero sí que ella permite una trascendencia de los límites de la subjetividad a través de la construcción de una obra o ideal común.

\section{Conclusiones: Amistad y comunidad auténtica}

De acuerdo a lo que hemos visto se puede concluir señalando que la concepción de la amistad de Nietzsche se relaciona profundamente al planteamiento de Aristóteles sobre la amistad al menos en tres aspectos fundamentales: a) Como Aristóteles, también Nietzsche ve en la amistad una virtud particular que, si bien no contribuye a alcanzar la felicidad en su sentido de eudaimonia, ciertamente contribuye fundamentalmente a alcanzar el ideal de su ética individual. Por otro lado, b) Nietzsche también sigue a Aristóteles en su consideración de la amistad como un ideal fundamental para la estructuración social y política de la vida humana. La amistad constituiría el grupo de "iguales" 
que, en tanto hablamos de igualdad por tratarse de "naturalezas fuertes", "soberanas" de su propia individualidad, no intentan conseguir seguidores ni menos homogenizar modos de ser o conductas. Se trata de un grupo de iguales, que permite justamente el espacio para una convivencia donde el ideal contemporáneo del "pluralismo ético" puede encontrar un suelo fecundo. En un punto adicional, c) Se observa una convergencia significativa en la función ética que cumple la amistad tanto en Aristóteles como en Nietzsche: Pues, pese a sus enormes diferencias, en ambos casos la amistad es considerada como ocasión de una optimización del individuo. Si bien en el caso de Aristóteles se trata directamente de un perfeccionamiento ético-moral, en el caso de Nietzsche tiene que ver con una optimización amoral o dicho en sus términos, en una trascendencia de los propios límites normativos, morales y culturales en vistas de un fortalecimiento de sus posibilidades vitales. El enemigo terrenal, visto siempre como posible amigo estelar, es justamente el compañero constante del sobre/superhombre. Evidentemente, ambos perfeccionamientos son distintos, pues mientras el perfeccionamiento ético aristotélico tiene una teleología definida, alcanzar una forma de vida específica (la vida teorética propia de la filosófica); la optimización-amoral de Nietzsche no busca alcanzar un tipo de vida definido y considerado virtuoso. Así visto, considerando el perspectivismo de las verdades y la naturaleza valórica cambiante de la realidad, la ética de la amistad de Nietzsche no solo es jovial, sino que, además, se muestra pluralista ante distintas concepciones del bien y del mal, abierta a la posibilidad constante de la transformación y revisión de los propios supuestos. Ahora bien, hacer del enemigo un posible amigo y viceversa, es de exclusiva particularidad de Nietzsche y su filosofía y ética de la vida.

\section{Referencias}

Aristóteles (2003). Ética Nicomáquea / Ética Eudemia. Madrid: Editorial Gredos.

Aurenque, Diana (2015). Das Posthumane und Nietzsches Übermensch: Eine Blasphemie gegen Gott. En Aufklärung und Kritik, 2, pp. 88-97.

Aurenque, Diana (2018). Die medizinische Moralkritik Friedrich Nietzsches. Genese, Bedeutung und Wirkung. Wiesbaden: Springer.

Diethe, Carol (2011). "Frauen". In Nietzsche-Handbuch: Leben - Werk Wirkung (pp. 50-56). Stuttgart/Weimar: Metzler Verlag. 
Figal, Günter (1999). Nietzsche. Eine philosophische Einführung. Frankfurt a.m.: Reclam Verlag.

Heidegger, Martin (1988). Vom Wesen der Wahrheit. $\mathrm{Zu}$ Platons Höhlengleichnis und Theätet (WS 1931/32). In H. Mörchen (Ed.), Tomo 34 (Gesamtausgabe 34). Frankfurt a.m: Vittorio Klostermann.

Helm, Bennett (2017). "Friendship". In E. N. Zalta (Ed.), The Stanford Encyclopedia of Philosophy. Disponible en: https://plato.stanford.edu/ archives/fall2017/entries/friendship/ [Consultado el 12 de abril de 2018].

Holst, Jonas (2011). "Facetas de amistad en la obra de Friedrich Nietzsche y en la ética filosófica del siglo XX". Instantes y Azares: Escrituras Nietzscheanas, 9, pp. 35-48.

Holst, Jonas (2013). "Ethik der Freundschaft. Über eine nachgelassene Idee im Nachlass Friedrich Nietzsches". Nietzscheforschung, 20, 1, pp. 379-390.

Hübenthal, Christoph. (2006²). Eudaimonismus. En Handbuch Ethik. Stuttgart/ Weimar: Metzler Verlag.

Jaspers, Karl $\left(1950^{3}\right)$. Nietzsche. Einführung in das Verständnis seines Philosophierens. Berlin: de Gruyter.

Kaufmann, Walter (19683). Nietzsche. Philosopher, Psychologist, Antichrist. New York: Vintage.

Lemke, Harald (2011). "Freundschaft". In Nietzsche-Handbuch: Leben - Werk - Wirkung (pp. 237-238). Stuttgart/Weimar: Metzler Verlag.

Müller, Armin et al. (1972). "Freundschaft". In Historisches Wörterbuch der Philosophie (pp. 1105-1114). Basel/Stuttgart: Schwabe \& Co Verlag II.

Nietzsche, Friedrich (1999). Ecce Homo. Kritische Studien Ausgabe 6 (KSA 6). Múnich: Deutscher Taschenbuch Verlag de Gruyter. 
Nietzsche, Friedrich (1999). Die fröhliche Wissenschaft. KSA 3. Múnich: Deutscher Taschenbuch Verlag de Gruyter. Español. (2014). La gaya ciencia, Obras Completas, Vol. III. Madrid: Editorial Tecnos.

Nietzsche, Friedrich (1999). Nachgelassene Fragmente 1875-1879. KSA 8. Múnich: Deutscher Taschenbuch Verlag de Gruyter. Español (2008). Fragmentos Póstumos 1875-1882, Vol. II. Madrid: Editorial Tecnos.

Nietzsche, Friedrich (1999). Nachgelassene Fragmente 1869-1874. KSA 7. Múnich: Deutscher Taschenbuch Verlag de Gruyter. Español (2010). Fragmentos Póstumos 1869-1974, Vol. I. Madrid: Editorial Tecnos.

Nietzsche, Friedrich (1999). Menschliches Allzumenschliches I y II. KSA 2. Múnich: Deutscher Taschenbuch Verlag de Gruyter. Español (2014). Humano demasiado humano. Obras Completas, Vol. III. Madrid: Editorial Tecnos.

Nietzsche, Friedrich (1999). Nachgelassene Fragmente 1880-1882. KSA 9. Múnich: Deutscher Taschenbuch Verlag de Gruyter. Español (2008). Fragmentos Póstumos 1875-1882, Vol. II. Madrid: Editorial Tecnos.

Nietzsche, Friedrich (1999). Morgenröthe. KSA 3. Múnich: Deutscher Taschenbuch Verlag de Gruyter. Español (2014). Aurora, Obras Completas, Vol. III. Madrid: Editorial Tecnos.

Platón (1871). Lisis. En de P. Azcárate (Ed.), Obras completas, Vol. II, Madrid. Disponible en: http://www.filosofia.org/cla/pla/azf02213.htm [Consultado el 12 de abril de 2018].

Santa-Maria, Andrés (2008). "El intelectualismo socrático y su recepción en Aristóteles". Nova tellus [online]. 26 (1), pp. 115-150. Disponible en: http://www.scielo.org.mx/scielo.php?script=sci_arttext\&pid=S0185$30582008000100004 \& \operatorname{lng}=$ es\&nrm=iso [Consultado el 12 de abril de 2018].

Schischkoff, Georgi (1991). "Freundschaft”. En Philosophisches Wörterbuch (220). Stuttgart: Kröner. 
Treiber, Hubert (2011). "Freunde". En Nietzsche-Handbuch: Leben - Werk Wirkung. (pp. 35-49). Stuttgart/Weimar: Metzler Verlag.

Windelband, Wilhelm (195715). Lehrbuch der Geschichte der Philosophie. Tübingen: Mohr Siebeck. 